\title{
ОЦЕНКА ВЗАИМОСВЯЗИ ФИНАНСОВОЙ УСТОЙЧИВОСТИ И СИСТЕМНОГО РИСКА КРУПНЕЙШИХ РОССИЙСКИХ БАНКОВ
}

Карминский А.М. ${ }^{1}$, Столбов М.И. ${ }^{2}$

В статье предложен подход к оценке взаимосвязи финансовой устойчивости и системного риска публичных кредитных организаций, основанный на каноническом корреляционном анализе (canonical correlation analysis, CCA). Преимущество данного подхода заключается в вычислении коэффициентов корреляции для двух наборов индикаторов, а также в возможности выявить наиболее влиятельные переменные внутри рассматриваемых наборов. Он реализован на примере Сбербанка и ВТБ за период с I квартала 2010 г. по III квартал 2015 г. Показано, что между наборами показателей финансовой устойчивости и системного риска существует тесная положительная связь в случае обоих банков. Коинтеграционный анализ выявил, что она направлена от системного риска к финансовой устойчивости. В наборе индикаторов системного риска наибольшее значение имеет SRISK - объем потерь в капитализации финансового института, связанных с 40\%-ным падением мирового фондового рынка в течение полугода.

Ключевые слова: системный риск, финансовая устойчивость, канонические корреляции, коинтеграция, модель авторегрессии и распределенных лагов

JEL: G21; G32

\section{Введение}

После глобального финансового кризиса 2008-2009 гг. существенно возросло значение макропруденциального подхода в регулировании банковской деятельности. Понятие системного риска - одна из центральных категорий данного подхода. Он может быть рассчитан как на страновом уровне, так и для отдельного финансового института. При этом универсальной методологии оценки системного риска и, как следствие, общепринятого индикатора нет: в настоящее время известны свыше 30 конкурирующих показателей (Bisias et al., 2012). Вместе с тем перенос акцента с анализа и агрегирования риска отдельных банков (микропруденциальный подход) на макропруденциальное регулирование оставляет открытым вопрос о соотношении традиционных показателей финансовой устойчивости (например, предусмотренных системой CAMELS) и индикаторов системного риска. Существенную методологическую сложность представляет множественный характер переменных в обеих группах, что означает необходимость выявления возможных связей между двумя наборами переменных.

В данной работе предложен подход к оценке таких зависимостей, базирующийся на расчете канонических корреляций (canonical correlation analysis, CCA). Этот метод был применен для анализа тесноты линейной связи между наборами переменных, характеризующих финансовую устойчивость и системный риск двух крупнейших по величине активов российских банков - Сбербанка (ПАО) и ВТБ (ПАО). Расчет канонических корреляций, сочетающий элементы корреляционного и факторного анализа, стал отправной точкой для выявления коинтеграционных зависимостей между финансовой устойчивостью и системным риском, а также для оценки относительного влияния отдельных индикаторов внутри двух наборов данных.

Далее осуществлен обзор литературы, посвященной взаимосвязи индикаторов финансовой устойчивости банков и системного риска, охарактеризованы метод канонических корреляций и используемые в исследовании данные, обобщены полученные эмпирические результаты. Также обсуждается их значимость с точки зрения риск-менеджмента на уровне самих банков и регулирующего воздействия Банка России.

\section{Обзор литературы}

Проблемы финансовой устойчивости российских банков достаточно подробно исследованы в литературе (Емельянов и Брюхова, 2013; Карминский и Костров, 2013; Kostrov and Karminky,

1. Д-р эконом. наук, профессор департамента финансов НИУ ВШЭ.

2. Д-р эконом. наук, профессор кафедры прикладной экономики МГИМО МИД России. 
2014). В меньшей степени разработана проблематика системного риска, где преобладают работы методологической направленности и обзоры зарубежных исследований (Говтвань и Мансуров, 2011; Мансуров, 2013; Щепелева 2014). Насколько известно, вообще отсутствуют исследования, в которых бы изучалась взаимосвязь финансовой устойчивости и системного риска российских банков. Это объяснимо, так как взаимосвязь между финансовой устойчивостью и системным риском недостаточно широко представлена и в зарубежной литературе. С помощью специализированных поисковых систем (ECONLIT, RePEc) удалось выявить менее десяти работ, в явном виде исследующих эту взаимосвязь.

Кляйноу и Нелл (Kleinow and Nell, 2015) изучали факторы системной значимости кредитных организаций по выборке европейских банков за 2007-2012 гг. В качестве зависимой переменной они использовали сводный показатель системного риска. Потенциальные предикторы системного риска были распределены по двум группам: 1) индивидуальные характеристики банков, основанные на бухгалтерской отчетности; 2) контрольные переменные, отражающие качество институтов и финансового регулирования. Панельный регрессионный анализ показал, что сводный показатель системного риска положительно зависит от удельного веса кредитного портфеля в совокупных активах. Результатом, противоречащим интуитивным ожиданиям, стало положительное влияние достаточности капитала первого уровня (Tier 1) на величину системного риска. В то же время было установлено, что показатель левереджа, хотя и имеет ожидаемый (положительный) знак в регрессионных моделях, в большинстве спецификаций не является статистически значимым. Аналогичное по методологии исследование, выполненное по выборке латиноамериканских банков, не подтвердило универсальную значимость достаточности капитала и доли кредитного портфеля в активах как факторов системного риска (Kleinow et al., 2015). Наиболее устойчивым предиктором системного риска оказалась депозитная база банков (отношение депозитов к валюте баланса): чем выше доля депозитов в пассивах, тем меньше величина системного риска. Важность обеспеченности банков ликвидностью для смягчения проблемы системного риска подчеркивается и в другом исследовании (López-Espinosa et al., 2013), где вместо доли депозитов в пассивах применялось отношение кредитов к депозитам.

К выводу об отсутствии проциклического влияния достаточности капитала на величину системного риска приходят Вальяскас и Кизи (Vallascas and Keasy, 2012), а также ван Ордта и Джоу (Van Oordt and Zhou, 2014). В обеих работах Tier 1 препятствует увеличению системного риска и характеризуется ожидаемым отрицательным знаком в регрессионных моделях. При этом первое исследование основано на европейских данных, а второе - на американских. Вальяскас и Кизи обнаружили положительное влияние доли просроченной задолженности на величину системного риска и отрицательный эффект - со стороны рентабельности собственного капитала (ROE). В работе ван Ордта и Джоу отмечается положительное влияние левереджа.

Кин и Жу (Qin and Zhu, 2014) анализируют взаимосвязь финансовой устойчивости и системного риска банков в странах БРИК. Их выборка включает 77 публичных кредитных организаций в указанных странах за 1999-2012 гг. Они подтверждают значимость левереджа и доли просроченной задолженности кредитного портфеля как факторов системного риска. Однако оба показателя характеризуются отрицательным знаком. Таким образом, делевередж и сокращение доли неработающих ссуд не приводят к смягчению проблемы системного риска в странах БРИК. Исследователи также обнаруживают проциклический эффект рентабельности активов (ROA).

Анализ имеющихся исследований свидетельствует об отсутствии перечня индикаторов финансовой устойчивости банков, которые были бы устойчиво связаны с показателями системного риска и согласовывались бы с теоретическими представлениями об этих зависимостях. Такой результат может быть отчасти обусловлен тем, что во всех работах выводы были сделаны на базе панельных методов, которые микшируют индивидуальные особенности банков. Когда выборка включает кредитные организации из различных стран, обобщения могут быть недостаточно обоснованны, несмотря на имеющиеся эконометрические техники контроля (фиксированные и случайные эффекты в панельных регрессиях). Вайб, Бостанжич и Ньюманн (Wei $\beta$, 
Bostandzic and Neumann, 2014) косвенно подтверждают справедливость этих рассуждений, говоря об отсутствии робастных предикторов системного риска в условиях международных финансовых кризисов.

В этой связи видится перспективным подход, предусматривающий анализ взаимосвязи финансовой устойчивости и системного риска на уровне отдельных банков. В рамках такого подхода с большей вероятностью можно ожидать наличие положительной связи между эрозией устойчивости финансового института и уровнем его системного риска. Индикаторы устойчивости, основанные на балансовых данных, и системного риска при этом не синхронизированы по частоте. Поэтому помимо выявления зависимости между ними целесообразно ставить вопрос о ее направлениях. На уровне предварительных гипотез можно предположить, что меры системного риска, базирующиеся на высокочастотных рыночных данных, будут влиять на динамику финансовой устойчивости. Между ними может наблюдаться и двунаправленная связь, если финансовые рынки инерционно воспринимают изменения бухгалтерских показателей публичных финансовых институтов.

\section{Методология и данные}

Взаимосвязь показателей финансовой устойчивости и системного риска оценивается для Сбербанка (ПАО) и ВТБ (ПАО) с помощью канонического корреляционного анализа. Этот метод позволяет вычислить коэффициент корреляции между двумя наборами данных, хотя бы один из которых включает более чем одну переменную.

С формальной точки зрения данный метод можно охарактеризовать следующим образом. Пусть имеются два набора переменных $X=\left(X_{1}, X_{2}, . . X_{n}\right)$ и $Y=\left(Y_{1}, Y_{2}, . . Y_{n}\right)$. Также пусть могут быть определены линейные комбинации из переменных, входящих в эти наборы, т.е.

$$
\begin{aligned}
& W_{1}=a_{1} X_{1}+a_{\mathfrak{1}} X_{2}+\ldots+a_{1 n} X_{n}, \\
& V_{1}=b_{1} Y_{1}+b_{\mathfrak{1}} Y_{2}+\ldots+b_{1 k} Y_{k} \cdot(2)
\end{aligned}
$$

Если $\rho_{1}$ - коэффициент корреляции между $W_{1}$ и $V_{1}$, то задача канонического корреляционного анализа состоит в определении таких значений $a_{\mathbb{I}}, a_{\mathfrak{2}}, . ., a_{1 n}$ и $b_{\mathbb{I}}, b_{\mathfrak{L}}, . ., b_{1 k}$, чтобы значение $\rho_{1}$ было максимальным. Пусть возможны $m$ пар линейных комбинаций из переменных: $\left(W_{1}, V_{1}\right)$ , $\left(W_{2}, V_{2}\right), . .,\left(W_{m}, V_{m}\right)$, тогда канонический корреляционный анализ возвращает максимальные значения $\rho_{1}, \rho_{2}, . ., \rho_{m}$. Очевидно, что число пар $m$ и, соответственно, канонических корреляций определяется количеством переменных в наборе с меньшим числом индикаторов, то есть $m=\min (k, n)$. При этом парные корреляции $\operatorname{Corr}\left(W_{j}, V_{i}\right), \operatorname{Corr}\left(V_{j}, V_{i}\right), \operatorname{Corr}\left(W_{j}, W_{i}\right)$ должны быть равны нулю для любых $j \neq i$. Посредством теста хи-квадрат определяется оптимальное число канонических корреляций (корней) ${ }^{1}$.

Канонический корреляционный анализ получил широкое распространение в экономической социологии и маркетинге. В финансовых исследованиях, насколько известно, он использовался главным образом для оценки взаимосвязи доходностей на фондовом рынке и макроэкономических переменных (Mazuruse, 2014).

В целях нашего анализа первый набор данных включает индикаторы финансовой устойчивости банков, а второй - показатели системного риска. В первый массив входят следующие переменные:

- доля неработающих ссуд в портфеле (NPL);

- доля резерва под обесценение кредитного портфеля в кредитном портфеле (PROVLOAN);

- $\quad$ отношение резерва под обесценение кредитного портфеля к неработающим ссудам

1. Более подробное изложение математической теории метода канонических корреляций в контексте его возможных экономических приложений см., например, в работе Борзых (Борзых, 2016). 
(COVRATIO);

- чистая процентная маржа (NIM);

- отношение расходов к операционному доходу (CI RATIO);

- отношение кредитного портфеля к депозитам (LD RATIO);

- $\quad$ рентабельность активов (ROA);

- рентабельность собственного капитала (ROE);

- достаточность капитала первого уровня (TIER 1);

- достаточность общего капитала (TIER 2).

Перечисленные показатели взяты из ежеквартальных финансовых отчетов Сбербанка и ВТБ и охватывают период с I квартала 2010 г. по III квартал 2015 г. (23 наблюдения).

Данные по системному риску (в среднем за квартал) этих банков получены с помощью специализированного pecypca Worldwide Measures Центра по изучению риск-менеджмента Высшей коммерческой школы Лозанны (Швейцария) ${ }^{1}$. Использовались следующие индикаторы системного риска:

- предельный ожидаемый дефицит (marginal expected shortfall, MES), который показывает чувствительность доходности акций банка к 40\%-ному падению мирового фондового рынка в течение полугода (Acharya et al., 2010);

- волатильность акций (VOLATILITY) банка, оцененная с помощью класса GARCH моделей

- значение беты акций (BETA);

- $\quad$ мера SRISK - потери в капитализации финансового института, связанные с 40\%-ным падением мирового фондового рынка в течение полугода;

- $\quad$ значение условной корреляции (CONDCORREL), вычисленное по модели динамической условной корреляции GARCH-DCC.

\section{Результаты}

В случае обоих банков значения первых канонических корреляций (корней) указывают на очень тесную линейную связь между двумя наборами данных. Для Сбербанка этот показатель равен 0,99 , а для ВТБ составляет 0,98. Оба коэффициента корреляции значимы на уровне $1 \%$. Судя по результатам теста хи-квадрат с последовательным исключением канонических корреляций, в дальнейшем анализе следует ориентироваться на первые корни (табл. 1).

Таблица 1

Результаты теста на статистическую значимость канонических коэффициентов корреляции между финансовой устойчивостью и системным риском для Сбербанка и ВТБ

\begin{tabular}{|c|c|c|c|c|c|c|}
\hline \multirow[b]{2}{*}{$\begin{array}{c}\text { Порядковый } \\
\text { номер кано- } \\
\text { нического } \\
\text { коэффициента } \\
\text { корпелянии }\end{array}$} & \multicolumn{3}{|c|}{ Сбербанк (ПАО) } & \multicolumn{3}{|c|}{ ВТБ (ПАО) } \\
\hline & $\begin{array}{c}\text { Величина } \\
\text { канонического } \\
\text { коэффициента } \\
\text { корреляции }\end{array}$ & $\begin{array}{l}\text { Статистика } \\
\text { хи-квадрат }\end{array}$ & $\begin{array}{c}\text { Значимость } \\
\text { (p-value) }\end{array}$ & $\begin{array}{c}\text { Величина } \\
\text { канонического } \\
\text { коэффициента } \\
\text { корреляции }\end{array}$ & $\begin{array}{l}\text { Статистика } \\
\text { хи-квадрат }\end{array}$ & $\begin{array}{c}\text { Значи- } \\
\text { мость } \\
\text { (p-value) }\end{array}$ \\
\hline корреслина & 0,99 & 111,86 & 0,00 & 0,98 & 87,67 & 0,00 \\
\hline 2 & 0,92 & 50,55 & 0,07 & 0,82 & 37,43 & 0,40 \\
\hline 3 & 0,80 & 23,57 & 0,49 & 0,74 & 21,94 & 0.58 \\
\hline 4 & 0,56 & 9,52 & 0,80 & 0,65 & 11,04 & 0,68 \\
\hline 5 & 0,51 & 4,24 & 0,64 & 0,46 & 3,28 & $\begin{array}{l}0,00 \\
077\end{array}$ \\
\hline
\end{tabular}

1. Методологию их вычисления см. подробнее http://www.crml.ch/index.php?id=53.

2. Для моделирования волатильности эксперты Центра по изучению риск-менеджмента отбирают для каждого из финансовых институтов наиболее оптимальную (в смысле статистических критериев) спецификацию из класса GARCH моделей, включая стандартную GARCH $(1,1)$ и модификации, учитывающие асимметрию волатильности (EGARCH, GJR-GARCH и др.). 
Соответствующие первым каноническим коэффициентам корреляции значения $\left(W_{1}, V_{1}\right)$ объясняют 68,6 и 70,7\% вариации в наборе переменных финансовой устойчивости и системного риска в случае Сбербанка. Для ВТБ это соотношение составляет 47,4\% и 68,7\%.

Вместе с тем канонические корреляции лишь фиксируют наличие линейной зависимости между списками переменных, не выявляя ее направление. При этом осведомленность о том, как направлена связь - от индикаторов финансовой устойчивости к системному риску или наоборот - представляется весьма полезной как с точки зрения кредитных организаций, так и регулятора.

Ответить на этот вопрос можно, изучив коинтеграционные свойства рядов $\mathrm{W}_{1}$ и $\mathrm{V}_{1}$, где первый соответствует финансовой устойчивости, а второй - системному риску. На рисунках $1 \mathrm{a}, 6$ представлена динамика этих рядов для Сбербанка и ВТБ за исследуемый период.

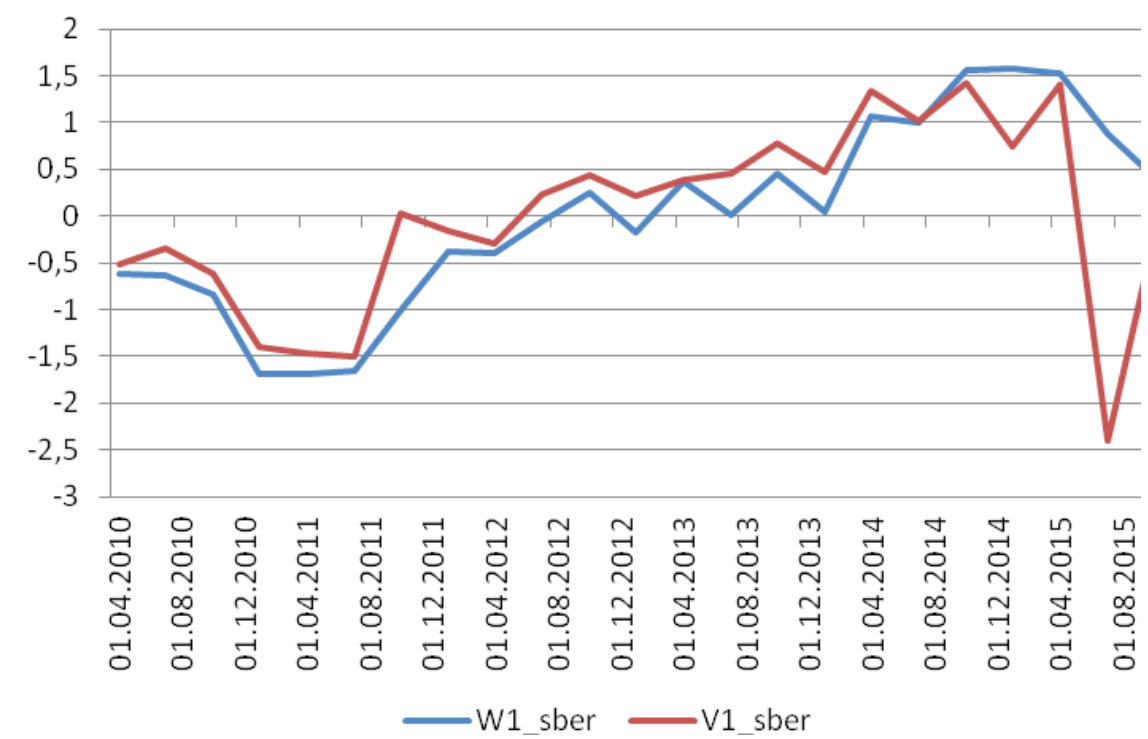

a)

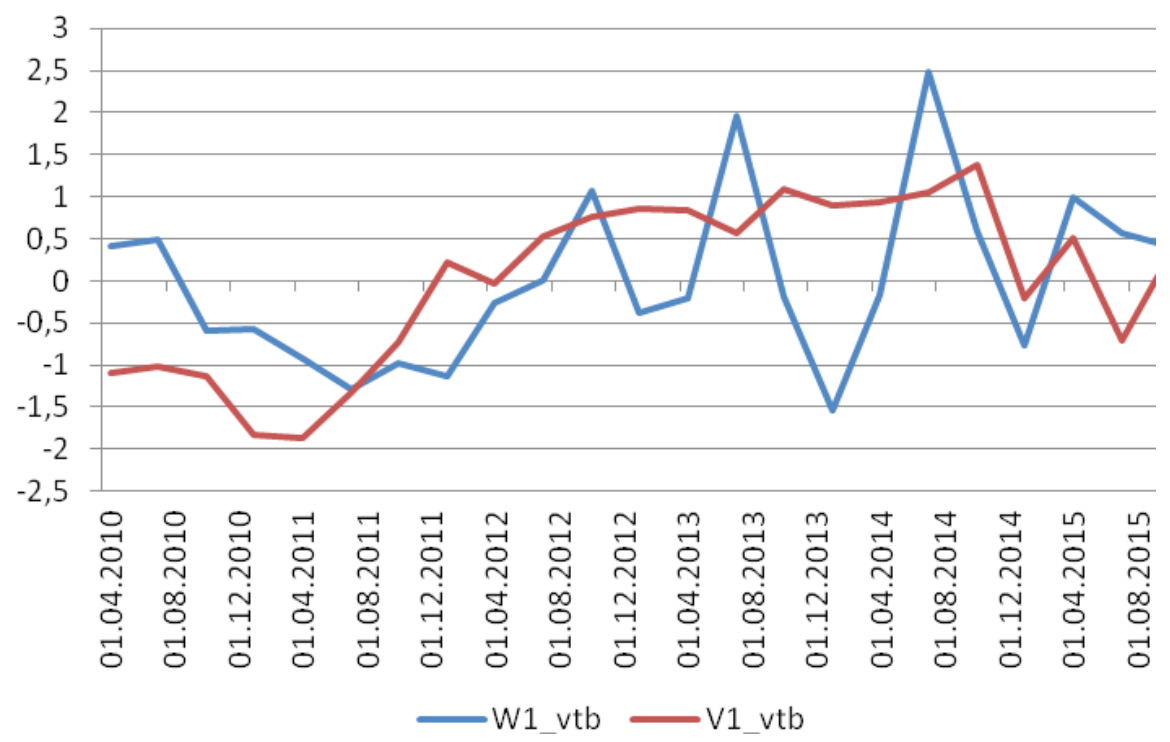

б)

Рисунок 1. Динамика рядов $W_{1}$ (финансовая устойчивость) и $V_{1}$ (системный риск) для Сбербанка (а) и ВТБ (б); I квартал 2010 2. -ІІІ квартал 2015 г.

В случае Сбербанка динамика рядов $\mathrm{W}_{1}$ и $\mathrm{V}_{1}$ синхронизирована в большей степени, чем для ВТБ. При этом для обеих кредитных организаций прослеживается нарастание уровня системного риска в период с лета 2011 г. до конца 2014 г. Также для Сбербанка есть выраженные признаки того, что изменения в $\mathrm{V}_{1}$ предшествуют изменениям в $\mathrm{W}_{1}$.

В качестве отправной точки коинтеграционного анализа проведен расширенный тест ДикиФуллера на единичный корень. Результаты данного теста указывают на то, что для обоих бан- 
ков ряды $\mathrm{W}_{1}$ и $\mathrm{V}_{1}$ не стационарны на конвенциональном пятипроцентном уровне значимости. При этом их первые разности стационарны (табл. 2).

Таблица 2

Результаты расширенного теста Дики-Фуллера для рядов финансовой устойчивости и системного риска Сбербанка и ВТБ

\begin{tabular}{|c|c|c|c|c|}
\hline & \multicolumn{2}{|c|}{ Уровень } & \multirow{2}{*}{\multicolumn{2}{|c|}{ Первые разности }} \\
\hline & t-статистика & Значимость (p-value) & t-статистика & \\
\hline $\mathrm{W}_{1-}$ sber & $-1,89$ & 0,33 & $-4,69$ & 0,00 \\
\hline $\mathrm{V}_{1}{ }_{1-}^{1-}$ sber & $-2,84$ & 0,08 & $-7,61$ & 0,00 \\
\hline $\mathrm{W}_{1-\mathrm{vtb}}$ & $-1,51$ & 0,51 & $-7,43$ & 0,00 \\
\hline $\mathrm{V}$ vtb & -1.68 & 0.43 & -6.50 & 000 \\
\hline
\end{tabular}

Таким образом, рассматриваемые ряды являются интегрированными порядка I(1), что позволяет ставить вопрос о присутствии коинтеграционных зависимостей. Обстоятельство, затрудняющее изучение этих зависимостей, - небольшая длительность рассматриваемых рядов. Традиционный подход Йохансена к оценке коинтеграционных отношений неприменим к таким коротким рядам. Альтернативой служит модель авторегрессии и распределенных лагов (ARDL). Эта эконометрическая техника используется для оценки коинтеграционных зависимостей между короткими временными рядами, применима к переменным порядка I(0) и I(1), допускает различное число оптимальных лагов изучаемых переменных. Для выявления коинтеграции на базе модели ARDL применяется тестирование границ Песарана (Pesaran et al., 2001). В рамках теста производится сравнение расчетной F-статистики для модели ARDL c оптимальным числом лагов с ее граничным значением для соответствующих условий модели (числа регрессоров и порядка интеграции). В случае превышения расчетной статистикой ее граничного значения переменные считаются коинтегрированными.

В нашем случае тест указывает на наличие коинтеграционной зависимости между финансовой устойчивостью и системным риском, когда последний выступает в качестве объясняющей переменной. Данный результат справедлив в отношении обоих банков (табл. 3).

Таблица 3

Результаты теста Песарана на коинтеграционную зависимость между финансовой устойчивостью и системным риском для Сбербанка и ВТБ

\begin{tabular}{|c|c|c|c|c|c|}
\hline $\begin{array}{c}\text { Зависимая пере- } \\
\text { менная }\end{array}$ & $\begin{array}{c}\text { Независимая } \\
\text { переменная }\end{array}$ & $\begin{array}{c}\text { Оптимальное } \\
\text { число лагов (по } \\
\text { критерию Шварца) }\end{array}$ & F-статистика & $\begin{array}{c}\text { Граничное значение } \\
\text { F-статистики на } \\
\text { уровне значимости } \\
5 \%\end{array}$ & $\begin{array}{c}\text { Наличие/отсут- } \\
\text { ствие коинтегра- } \\
\text { ции (+/-) }\end{array}$ \\
\hline W1_sber & V1_sber & ARDL(2,1) & 8,74 & 5,73 & + \\
V1_sber & W1_sber & ARDL(2,2) & 3,48 & - \\
W1_vtb & V1_vtb & ARDL(3,3) & 9,96 & & + \\
V1_vtb & W1_vtb & ARDL(3,0) & 1,56 & & - \\
\hline
\end{tabular}

Таким образом, динамика системного риска выступала драйвером изменения финансовых коэффициентов Сбербанка и ВТБ в 2010-2015 гг. Полученный результат актуализирует задачу по организации мониторинга системного риска как со стороны самих кредитных организаций, так и регулятора. Он согласуется с предварительными ожиданиями, так как индикаторы системного риска, свернутые при помощи канонического корреляционного анализа в показатель $\mathrm{V}_{1}$, рассчитываются на базе ежедневных показателей фондового рынка, тогда как переменные, характеризующие финансовую устойчивость, основаны на квартальных данных.

С помощью канонического корреляционного анализа можно определить наиболее значимые переменные внутри наборов, соответствующих финансовой устойчивости и системному риску. Их выявляют путем оценки факторной структуры показателей $\mathrm{W}_{1}$ и $\mathrm{V}_{1}$. По сути, эта процедура тождественна расчету нагрузок при обычном факторном анализе и подразумевает вычисление корреляций исходных переменных внутри каждого набора с $\mathrm{W}_{1}$ или $\mathrm{V}_{1}$. При этом решающее значение отводится абсолютному значению коэффициента корреляции, а не его знаку. Результаты анализа факторной структуры финансовой устойчивости и системного риска для Сбербанка и ВТБ приведены в таблицах 4 и 5. 
Факторная структура финансовой устойчивости и системного риска Сбербанка

\begin{tabular}{|c|c|c|c|}
\hline $\begin{array}{l}\text { Исходные индикаторы финансовой устойчи- } \\
\text { вости }\end{array}$ & $\begin{array}{l}\text { Корреляция с } \\
\text { W sber }\end{array}$ & $\begin{array}{c}\text { Исходные индикаторы систем- } \\
\text { ного риска }\end{array}$ & Корреляция с $V_{1-}$ sber \\
\hline Доля неработающих ссуд в портфеле (NPL) & $-0,57$ & $\begin{array}{c}\text { Предельный ожидаемый } \\
\text { дефицит (MES) }\end{array}$ & 0,35 \\
\hline $\begin{array}{c}\text { Доля резерва под обесценение кредитного } \\
\text { портфеля в кредитном портфеле (PROVLOAN) }\end{array}$ & $-0,72$ & $\begin{array}{l}\text { Волатильность котировок } \\
\text { акций (VOLATILITY) }\end{array}$ & 0,55 \\
\hline $\begin{array}{c}\text { Отношение резерва под обесценение кре- } \\
\text { дитного портфеля к неработающим ссудам } \\
\text { (COVRATIO) }\end{array}$ & $-0,50$ & Бета (ВЕТА) & 0,44 \\
\hline Чистая процентная маржа (NIM) & $-0,78$ & $\begin{array}{c}\text { Потери в капитализации } \\
\text { (SRISK) }\end{array}$ & 0,89 \\
\hline $\begin{array}{l}\text { Отношение расходов к операционному доходу } \\
\text { (CI RATIO) }\end{array}$ & $-0,16$ & $\begin{array}{l}\text { Динамическая условная кор- } \\
\text { реляция (CONDCORREL) }\end{array}$ & $-0,72$ \\
\hline $\begin{array}{l}\text { Отношение кредитного портфеля к депозитам } \\
\text { (LD RATIO) }\end{array}$ & $\begin{array}{l}0,76 \\
-0,86\end{array}$ & & \\
\hline $\begin{array}{c}\text { Рентабельность активов (ROA) } \\
\text { Рентабельность собственного капитала (ROE) }\end{array}$ & $-0,82$ & & \\
\hline $\begin{array}{c}\text { Достаточность капитала первого уровня } \\
\text { (TIER1) }\end{array}$ & $-0,94$ & & \\
\hline Достаточность обшего капитала (TIER2) & $-0,83$ & & \\
\hline
\end{tabular}

Таблица 5

Факторная структура финансовой устойчивости и системного риска ВТБ

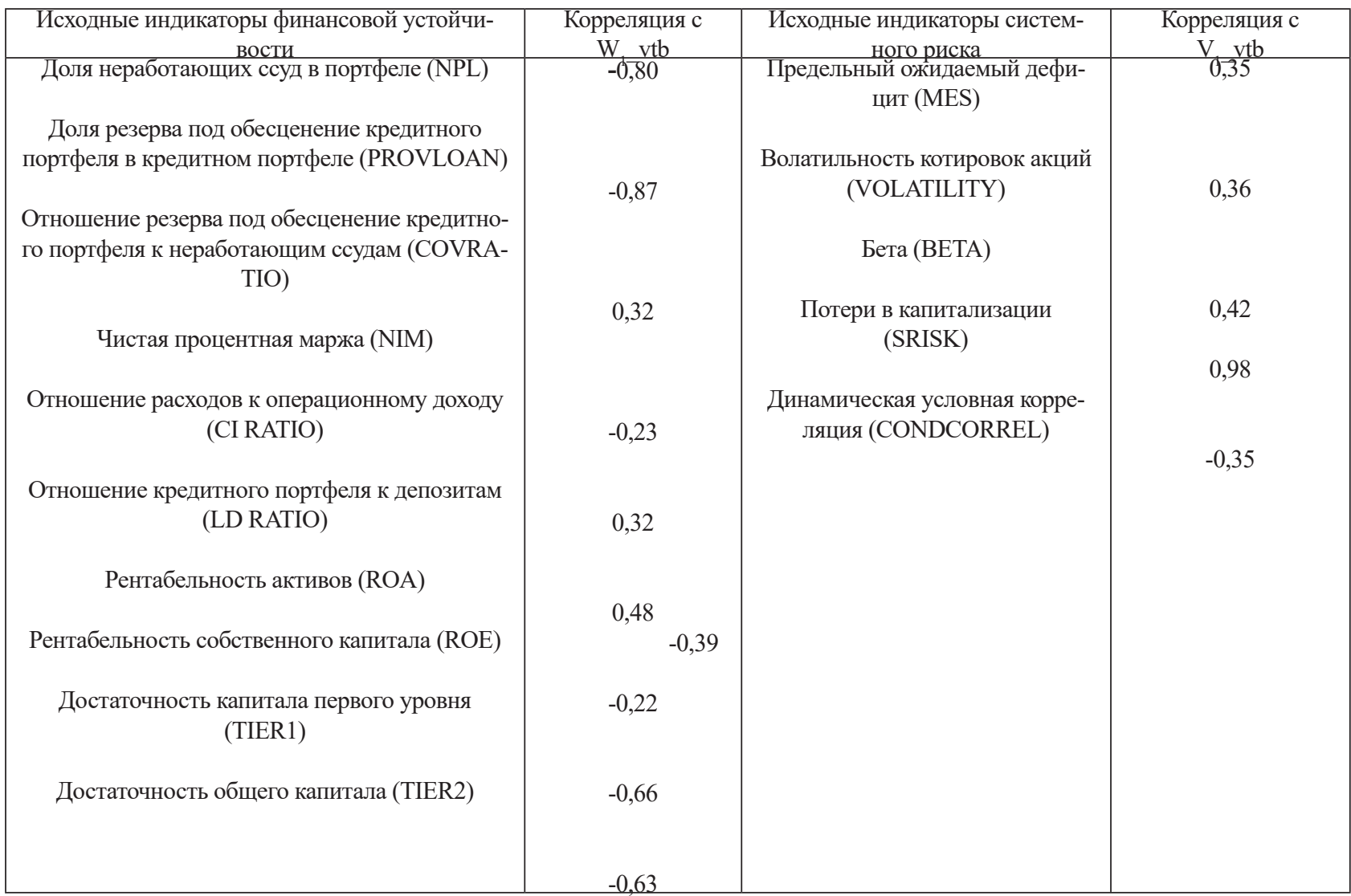

Что касается набора характеристик системного риска, то для обоих банков приоритетную роль играет показатель SRISK, существенно превосходя альтернативные индикаторы по тесноте связи с $\mathrm{V}_{1}$.

Наибольшее влияние на комплексную оценку финансовой устойчивости Сбербанка ( $\mathrm{W}_{1}$ sber) оказывают индикаторы достаточности капитала и рентабельности (TIER1, ROA, TIER2, ROE). 
В случае ВТБ ключевое значение имеют переменные, характеризующие качество кредитного портфеля (PROVLOAN, NPL). Несколько меньшая роль принадлежит показателям достаточности капитала (TIER1, TIER2). По-видимому, такие результаты следует связывать с различиями в бизнес-моделях Сбербанка и ВТБ. В частности, следует принимать во внимание большую диверсификацию и сбалансированность кредитного портфеля Сбербанка на фоне агрессивной кредитной политики ВТБ. Банковскую группу ВТБ отличают большая ориентированность на привлечение заемщиков с «открытого» рынка потребительского кредитования (прежде всего за счет ВТБ 24 и Лето банка), тогда как Сбербанк преимущественно продвигает кредитные продукты своим клиентам - физическим лицам по зарплатным проектам. Также имеются различия и в подходах к управлению «плохими» кредитами: ВТБ не списывает эти кредиты по истечении 180 дней, а продолжает учитывать. Вероятно, оказывает влияние и отраслевое распределение заемщиков - юридических лиц: в портфеле ВТБ более существенная доля приходится на уязвимые к циклическим спадам сектора, такие как строительство и розничная торговля (14 и 8\% (Годовой отчет Группы ВТБ за 2014 год, с. 7) против 4,9 и 14\% ${ }^{1}$ у Сбербанка по итогам 2014 г. (Итоги деятельности Группы Сбербанк по МСФО за 2014 год, с. 19).

В целом проведенный анализ факторных структур уточняет, через какие индикаторы финансовой устойчивости банков наиболее вероятно проявление системного риска.

\section{Заключение}

Предложенный подход к оценке взаимосвязи финансовой устойчивости и системного риска применительно к двум крупнейшим российским банкам включает черты корреляционного и факторного анализа. Расчет канонических корреляций позволяет, с одной стороны, определить степень тесноты линейной связи между наборами переменных, а с другой - выявить наиболее влиятельные показатели внутри этих списков. Тем самым он эффективен как разновидность факторного анализа и может быть использован в задачах снижения размерности данных.

В рассмотренных кейсах коэффициенты финансовой устойчивости Сбербанка и ВТБ оказались тесно коррелированными с набором показателей системного риска. Коинтеграционный анализ свидетельствует о том, что для обоих банков взаимосвязь направлена именно от показателей системного риска к индикаторам финансовой устойчивости. При этом наиболее влиятельной мерой системного риска оказался SRISK, тогда как в наборе показателей финансовой устойчивости результаты оказались неоднородными. Приоритетное значение для Сбербанка имеют показатели достаточности капитала и рентабельности, а для ВТБ - характеристики качества ссудного портфеля.

Дальнейший анализ взаимосвязи финансовой устойчивости и системного риска на уровне отдельных кредитных организаций, очевидно, может развиваться по двум магистральным направлениям: расширения круга анализируемых банков (ограниченного числом публично котируемых, что критично для вычисления подавляющего большинства показателей системного риска) и включения дополнительного числа индикаторов в оба набора.

\section{Список литературы}

1. Борзых Д.А. О методе канонических корреляций: препринт WP2/2016/01. Серия WP2 «Количественный анализ в экономике. М.: Изд. дом Высшей школы экономики, 2016. .$-18 \mathrm{c}$.

2. Говтвань О.Дж., Мансуров А.К. Системный риск в финансовой сфере: теоретический анализ и подходы к оцениванию // Проблемы прогнозирования. 2011. № 2. С. 24-36.

3. Годовой отчет Группы ВТБ за 2014 год. URL:http://www.vtb.ru/upload/iblock/9e9/Annual report_2014.pdf

4. Емельянов А.М., Брюхова О.О. Оценка вероятности банкротства банка // Финансы и кредит. 2013. № 27(555). С. 47-58.

1. Итоги деятельности Группы Сбербанк по МСФО за 2014 год. URL: http://sberbank.ru/common/img/uploaded/files/info/ ifrs2014/SBERBANK_GROUPS IFRS RESULTS_YE14_RUS.pdf. C.19. 
5. Итоги деятельности Группы Сбербанк по МСФО за 2014 год. URL: http://sberbank. ru/common/img/uploaded/files/info/ifrs2014/SBERBANK_GROUPS_IFRS_RESULTS YE14 RUS.pdf.

6. Карминский А.М., Костров А.В. Моделирование вероятности дефолта российских банков: расширенные возможности // Журнал Новой экономической ассоциации. 2013. № 1(17). C. $64-86$.

7. Мансуров А.К. Роль системного риска в распространении и нарастании экономической нестабильности // Проблемы прогнозирования. 2013. № 4. С. 97-109.

8. Щепелева М.А. Подходы к оценке риска финансового сектора // Вестник МГИМОУниверситета. 2014. № 6(39). С. 117-125.

9. Acharya, V., Pedersen, L.H., Philippon, T., and Richardson, M.P. (2010), "Measuring systemic risk". Available at SSRN http://dx.doi.org/10.2139/ssrn.1573171.

10. Bisias, D., Flood, M., Lo, A.W., and Valavanis, S. (2012), “A survey of systemic risk analitycs”, Annual Review of Financial Economics, vol. 4, pp. 255-296.

11. Kleinow, J., and Nell, T. (2015), "Determinants of systemically important banks: the case of Europe", Mimeo.

12. Kleinow, J., Horsch, A., and García-Molina, M. (2015), "Factors driving systemic risk of Banks in Latin America", Journal of Economics and Finance, DOI: forthcoming, doi 10.1007/ s12197-015-9341-7.

13. Kostrov, A.V., and Karminsky, A.M. (2014), "Comparison of bank financial stability factors in CIS Countries”, Procedia Computer Science, vol. 31, pp. 766-772.

14. López-Espinosa, G., Rubia, A., Valderrama, L., Antón, M. (2013), “Good for one, bad for all: determinants of individual versus systemic risk", Journal of Financial Stability, vol. 13, pp. 287-299.

15. Mazuruse, P. (2014), "Canonical correlation analysis: macroeconomic variables versus stock returns", Journal of Financial Economic Policy, vol. 6(2), pp. 179-196.

16. Pesaran, M., Shin, Y., Smith, R. (2001), "Bounds testing approaches to the analysis of level relationships", Journal of Applied Econometrics, vol. 16, pp. 289-326.

17. Qin, X., and Zhu, X. (2014), “Too non-traditional to fail? Determinants of systemic risk for BRICs Banks", Applied Economics Letters, vol. 21(4), pp. 261-264.

18. Vallascas, F., and Keasy, K. (2012), "Bank resilience to systemic shocks and the stability of banking systems: small is beautiful”, Journal of International Money and Finance, vol. 31, pp. $1745-1776$.

19. Van Oordt, M., and Zhou, C. (2014), "Systemic risk and bank business models", DNB Working Paper № 442, October.

20. Wei $\beta$, G., Bostandzic, D., and Neumann, S. (2014), "What factors drive systemic risk during international financial crises?" Journal of Banking \& Finance, vol. 41, pp. 78-96. 
ASSESSING THE LINK BETWEEN FINANCIAL SOUNDNESS

AND SYSTEMIC RISK FOR KEY RUSSIAN BANKS

\author{
Alexander M. Karminsky, \\ Dr. of Economics, Professor, Department of Finance, \\ National Research University Higher School of Economics
}

Mikhail I. Stolbov,

Dr. of Economics, Professor, Department of Applied Economics, Moscow State Institute of International Relations (University)

\begin{abstract}
The paper introduces the approach to assessing the link between two sets of indicators - financial soundness and systemic risk. It is based on canonical correlation analysis and applies to key publicly traded Russian banks - Sberbank and VTB for the period 2010:1q-2015:3q. The financial soundness indicators are sourced from quarterly financial statements while systemic risk measures come from the Center for Risk Management database (HEC Lausanne).

The methodology is instrumental both in measuring linear dependencies between two sets of indicators and as a tool of factor analysis, enabling to identify the most influential variables within these sets. Namely, for the banks in question very high positive correlations are observed between financial soundness and systemic risk. The ARDL estimator and bounds cointegration test show that systemic risk leads the set of financial soundness indicators. The finding can largely be attributed to the underlying high frequency structure of systemic risk data while financial soundness is discrete and measured on quarterly basis. It also accentuates the importance of monitoring systemic risk for Russian banks. The SRISK metric corresponding to the capital shortfall as a result of the $40 \%$ decline of the world stock market appears to play a pivotal role within the set of systemic risk indicators.
\end{abstract}

Keywords: systemic risk, financial soundness, canonical correlations, cointegration, ARDL model

JEL: G21; G32

\title{
References
}

1. Borzykh, D.A. (2016), "On the method of canonical correlations", Working paper WP2/2016/01, National Research University Higher School of Economics, Moscow: Higher School of Economics Publ. House. (Series WP2 "Quantitative Analysis of Russian Economy"). -18 p.

2. Govtvan' O.Dzh., and Mansurov,A.K.(2011), "Sistemnyj risk v finansovoj sfere: teoreticheskij analiz i podhody k ocenivaniju”, Problemy prognozirovanija, vol. 2, pp. 24-36.

3. VTB Group annual report 2014 http://www.vtb.ru/upload/iblock/9e9/Annual_report_2014. pdf

4. Emel'janov, A.M., and Brjuhova, O.O. (2013), "Ocenka verojatnosti bankrotstva banka", Finansy $i$ kredit, vol. 27, no. 555, pp. 47-58.

5. IRFS results of Sberbank Group for 2014. http://sberbank.ru/common/img/uploaded/files/ info/ifrs2014/SBERBANK_GROUPS_IFRS_RESULTS_YE14_RUS.pdf

6. Karminskij, A.M., and Kostrov, A.V. (2013), "Modelirovanie verojatnosti defolta rossijskih bankov: rasshirennye vozmozhnosti”, Zhurnal Novoj jekonomicheskoj associacii, vol. 1, no. 17, pp. 64-86.

7. Mansurov, A.K. (2013), "Rol' sistemnogo riska v rasprostranenii i narastanii jekonomicheskoj nestabil'nosti”, Problemy prognozirovanija, vol. 4, pp. 97-109.

8. Schepeleva, M.A. (2014), "Podhody k ocenke riska finansovogo sektora", Vestnik MGIMOUniversiteta, vol. 6, no. 39, pp. 117-125. 
9. Acharya, V., Pedersen, L.H., Philippon, T., and Richardson, M.P. (2010), "Measuring Systemic Risk” Available at SSRN http://dx.doi.org/10.2139/ssrn.1573171.

10. Bisias, D., Flood, M., Lo, AW., and Valavanis, S. (2012), "A Survey of Systemic Risk Analitycs”, Annual Review of Financial Economics, vol. 4, pp. 255-296.

11. Kleinow, J., and Nell, T. (2015), "Determinants of Systemically Important Banks: the Case of Europe", Mimeo.

12. Kleinow, J., Horsch, A., and García-Molina, M. (2015), "Factors Driving Systemic Risk of Banks in Latin America", Journal of Economics and Finance, forthcoming, doi 10.1007/ s12197-015-9341-7.

13. Kostrov, A.V., and Karminsky, A.M. (2014), "Comparison of Bank Financial Stability Factors in CIS Countries", Procedia Computer Science, vol. 31, pp. 766-772.

14. López-Espinosa, G., Rubia, A.,Valderrama, and Antón, M. (2013), “Good for One, Bad for All: Determinants of Individual versus Systemic Risk", Journal of Financial Stability, vol. 13, pp. 287-299.

15. Mazuruse, P. (2014), "Canonical Correlation Analysis: Macroeconomic Variables versus Stock Returns”, Journal of Financial Economic Policy, vol. 6, no. 2, pp. 179-196.

16. Pesaran, M., Shin, Y., and Smith, R. (2001), "Bounds Testing Approaches to the Analysis of Level Relationships", Journal of Applied Econometrics, vol. 16, pp. 289-326.

17. Qin, X., and Zhu, X. (2014), “Too Non-traditional to Fail? Determinants of Systemic Risk for BRICs Banks", Applied Economics Letters, vol. 21, no.4, pp. 261-264.

18. Vallascas, F., and Keasy, K. (2012), "Bank Resilience to Systemic Shocks and the Stability of Banking Systems: Small is Beautiful", Journal of International Money and Finance, vol. 31, pp. 1745-1776.

19. Van Oordt, M., and Zhou, C. (2014), "Systemic Risk and Bank Business Models", DNB Working Paper № 442, October.

20. Weiß, G., Bostandzic, D., andNeumann, S. (2014), "What Factors Drive Systemic Risk during International Financial Crises?” Journal of Banking \& Finance, vol. 41, pp. 78-96. 